\title{
Ebeveynlerin Alerjik Astım Nedenleri Hakkındaki Bilgi Düzeylerinin ve Uygulanan Tedaviye Yaklaşımlarının Değerlendirilmesi
}

\author{
Evaluation of Parents' Level of Knowledge About the Causes of Allergic Asthma \\ and Their Perspective on Treatment

\section{Pinar ATLA ${ }^{1}$, Pinar ERGENEKON $^{2}$, Özlem ERDEDE ${ }^{3}$, Erdal SARI $^{3}$ Hülya Ercan SARIÇOBAN ${ }^{4}$}

1. Bezm-i Alem Vaklf Üniversitesi Tip Fakültesi, İstanbul, Türkiye

2. Marmara Üniversitesi Tip Fakültesi, İstanbul, Türkiye

3. Zeynep Kamil Kadın Doğum ve Çocuk Eğitim Araştırma Hastanesi , Istanbul, Türkiye

4. Yeditepe Üniversitesi Tip Fakültesi, İstanbul, Türkiye

\section{ÖZET}

Amaç: Astım, çeşitli uyaranlara karşı gelişen hava yolu aşırı duyarlılı̆̆ ile iliskili kronik hava yolu inflamasyonu ile karakterize bir hastalıktır. Kötü kontrollü astımın önemli belirleyicilerinden bazıları evdeki evcil hayvanlar, hava kirliliği, polen maruziyeti gibi çevresel faktörlerdir. Calıșmamızda ebeveynlerin astımı ortaya çıkaran etkenler, ataklardan korunmak için alınabilecek önlemler ve astım için ilaç kullanımı hakkındaki bilgi düzeylerini ölçmeyi amaçladık.

Gereçler ve Yöntem: Ocak 2015 -Haziran 2016 tarihleri arasinda Zeynep Kamil Hastanesi hasta çocuk polikliniğine herhangi bir nedenle bașvuran hasta yakınlarına astım bilgi düzeyini ölçmeyi hedeflediğimiz anket formu uyguland. Ankette hasta ve hasta yakınlarının demografik özelliklerinin yanısıra alerjik hastalık/astım varlığı, varsa astım için kullanılan ilaçlar , alerjik astımı ortaya çıkaran etkenler ve astımdan korunmak için alınabilecek önlemler sorgulandi. Hasta yakınları etkenler ve önlemler için birden fazla cevaplama yapabildiler.

Bulgular: Çalışmaya yaşları 20-49 arasında, 781 kadın ve 219 erkek olmak üzere toplam 1000 hasta yakın dahil edildi. Hastaların ortalama yaşları 4,5 $\pm 2,2$ yıl idi. Çalışmaya dahil edilen ebeveynlerin 169'unda alerjik hastalı mevcutken, 61 ebeveyn astım nedeniyle inhaler tedavi kullanmaktaydı. Çocuğunda alerjik hastalık olanların sayısı 149 idi. Astım/alerjik bronșit olan 114 hastanın 74'ü erkek olup ortalama yașı 4,4 3,06 yıl idi. Astımı ortaya çıkardığı düşünülen etkenler sorusuna en sık $(\% 50,1)$ bilmiyorum cevabı verilirken; çocuğu astımdan korumak için alabilecekleri önlemler sorusuna da en sık (\%52) bilmiyorum cevabı verildi. Cocuğunda alerjik hastalığ olanlarda çocuğunda alerjik hastalığ olmayanlara göre astım ataklarinin ev tozu, polen, rutubet, evcil hayvan, kirli hava, sigara, küf ve gıdadan kaynakl olduğunu düşünenlerin oranları istatistiksel olarak anlaml derecede daha yüksek ve bu soruya bilmiyorum cevabı verenlerin oranı istatistiksel olarak anlaml derecede daha düşüktü $(p<0,001)$.

Sonuç: Çocuğunda alerjik hastalık mevcut olan hasta yakınlarının alerjik astımı ortaya çıkaran etkenler ve astımdan koruyuси önlemler konusunda bilgi düzeyleri diğer hasta yakınlarına kıyasla daha yüksektir. Ancak tüm çalışmadaki ebeveynler degerlendirildiğinde astım etkenleri ve koruyucu önlemler sorularına verilen "bilmiyorum" cevabının fazlalı̆̆ bilgi düzeyinin yeterli olmadiğını göstermektedir.

\section{İletișim}

Sorumlu Yazar: Pınar ERGENEKON

Adres: Marmara Üniversitesi Pendik Eğitim Araștırma Hastanesi, Fevzi Çakmak Mah. Mimar Sinan Cad. No: 41 Pendik İstanbul, Türkiye Tel: +90 (216) 6254545

E-Posta: drpergenekon@hotmail.com

Makale Geliș: 03.06.2020

Makale Kabul: 08.06.2020

DOI: http://dx.doi.org/10.16948/zktipb.747622
Ebeveynler havayolu hassasiyeti olan çocukları için çoğunlukla alerjik bronşit tanımını kullanmayı seçmişlerdi. Astım tanisı aileler için belki de ürkütücü, tedavisi zor, kronik bir hastalık olarak düşünüldüğ̈̈nden bu tanımlamayı daha az tercih etmişlerdi. Astım tedavisi ve kontrolü için ebeveynlerin bilgi düzeyinin artırlmast gerekmektedir.

Anahtar Kelimeler: astım, alerji, ebeveyn

\section{ABSTRACT}

Objective: Asthma is a disease characterized by chronic airway inflammation associated with airway hypersensitivity. One of the important determinants of poorly controlled asthma is environmental factors such as pets, air pollution and pollen exposure. In our study, we aimed to measure the parents' level of knowledge about the causes of asthma and preventive factors.

Material and Methods: Between January 2015-June 2016, a questionnaire was conducted in which we aim to measure asthma knowledge level of the parents who applied to Zeynep Kamil Hospital outpatient clinic for any reason. In the questionnaire, the demographic characteristics of the patients and their parents and also the presence of allergic disease / asthma, the drugs used for asthma, the causes of asthma, and the preventive factors of asthma were questioned. The parents were able to mark more than one option for causes and factors.

Results: A total of 1000 parents, 781 females and 219 males, aged between 20-49 years were included in the study. The mean age of the patients was 4,5 $\pm 2,2$ years. While 169 of the parents included in the study had allergic disease, 61 were using inhaler therapy due to asthma. The number of children with allergic disease was 149. Of the 114 patients with asthma or allergic bronchitis, 74 were male, with a mean age of 4,4 $\pm 3,06$ years. The most common (50.1\%) answers about the factors that are thought to be the cause of allergic asthma and the the preventive factors of asthma (52\%) were "I don't know." The response ratio of the parents whose children have allergic disease and who think that asthma is caused by house dust, pollen, humidity, pet, dirty air, foods, tobacco exposure and mold compared to those without allergic diseases was statistically significantly higher and the rate of those whose answer was "I don't know" was statistically significantly lower $(p<0.001)$.

Conclusion: The parents whose children have allergic disease have higher levels of knowledge about asthma compared to other parents.

But all parents' level of knowledge about asthma is not sufficient. Parents choose to use mostly allergic bronchitis for their children with airway sensitivity. The diagnosis of asthma was less favorable for families because it was thought to be a scary, difficult to treat, chronic disease. For the treatment and control of asthma, the knowledge level of parents should be increased.

Keywords: asthma, allergy, parent 


\section{GíRIŞ}

Astım, birtakım uyaranlara karşı gelişen hava yolu aşırı duyarlılı̆̆ lamasyonu ile karakterize bir hastalıktır (1). Astımın ortaya ç1kmasında etkili risk faktörlerinin başında genetik faktörler gelirken, genlerin hem kendi aralarında, hem de çevresel faktörler ile etkileşerek bireyin astıma eğilimini artırdıkları düşünülmektedir $(2-4)$.

Evcil hayvanlar, polen maruziyeti, hava kirliliği gibi çevresel faktörler ile temasın azaltılması hem astım gelişiminin önlenmesi hem de hastalık gelişmiş kişilerde atakların kontrol altına alınabilmesi açısından önem taşımaktadır (5-7).

Astım tedavisinde hasta veya ebeveyn/bakımverici ile hekim arasındaki işbirliğinin büyük önemi vardır. Bu işbirliği ile astımlı hastanın veya ebeveynin bilgilenip, gerekli becerileri edinerek astım tedavisinde önemli bir rol oynaması sağlanmalıdır (4, 8).

Yapılan bazı çalışmalar ebeveynlerin astım kontrolü üzerindeki etkisine odaklanmıştır. Hastaların veya ebeveynlerin çevresel faktörlerden uzak kalma ve tedavi yöntemlerini anlama konularında eğitim aldıklarında astımın klinik seyrinin düzeldiği görülmüştür (9-12).

Çalışmamızda uyguladığımız anket ile ebeveynlerin özellikle alerjik astımı ortaya çıkaran etkenler ve atakları önlemek için alınabilecek önlemler hakkındaki bilgi düzeylerini ölçmeyi amaçladık.

\section{GEREÇ ve YÖNTEM}

Ocak 2015-Haziran 2016 tarihleri arasında Zeynep Kamil Hastanesi hasta çocuk polikliniğine herhangi bir nedenle başvuran hasta yakınlarına astım bilgi düzeyini ölçmeyi hedeflediğimiz anket formu uygulanmıştır. Anket formu 4 bölüm halinde hazırlanmıştır. 1. Bölümde hasta ve ebeveynlerin demografik özelliklerinin sorgulandığ1 6 soru (hasta yaşı, ebeveyn yaşı, hasta cinsiyeti, ebeveyn cinsiyeti, ebeveyn eğitim durumu, ebeveynin çocuk say1s1) mevcuttu. 2. bölümde ebeveynlerde alerjik hastalık varlığı ve inhaler tedavi kullanımı ile çocuklarında alerjik hastalık (astım/alerjik bronşit/egzema/ürtiker/saman nezlesi ) varlığ 1 sorgulandı. 3 . Bölümde astım tedavisinde kullanılan ilaçlarla ilgili bilgi durumunu değerlendirmeye yönelik 3 soru; 4 . bölümde ise alerjik hastalarda "astımı ortaya çıkaran etkenler" ve "astım atağından korunmak için alınabilecek önlemler” olmak üzere 2 adet açık uçlu soru mevcuttu. Hasta yakınları etkenler ve önlemler için birden fazla cevaplama yapabildiler. Hasta yakınlarına sorular okunarak verdikleri cevaplar tarafimızca kayıt edildi. Çalışma için Zeynep Kamil Eğitim Araştırma Hastanesi Etik Kurulu'ndan onay alınd1. Katılımc1lara öncesinde bilgilendirme yapıld1 ve onamları alınd.

Çalışmada elde edilen verilerin değerlendirilmesinde istatistiksel analiz için SPSS (Statistical Package for Social Sciences) paket program1 15.0 versiyonu kullanıld1. Tanımlayıcı istatistiksel metotların (ortalama, standart sapma, median, minimum, maksimum gibi) yanı sıra grupların karşılaş- tırıldığ için Student T test ile Mann-Whitney U test ve kategorik değişkenler için Ki-kare ile Fisher exact test kullanıldı. Sonuçlar \%95 güven aralığında, anlamlıl1k $\mathrm{p}<0,05$ düzeyinde kabul edilerek değerlendirildi $(* \mathrm{p}<0,05 * * \mathrm{p}<0,01 * * * \mathrm{p}<0,001)$.

\section{BULGULAR}

Çalışmaya yaşları 20-49 arasında, 781 kadın ve 219 erkek olmak üzere toplam 1000 ebeveyn dahil edildi. Hastaların ise 673'ü erkek ,ortalama yaşlar1 4,5 \pm 2,2 y1l idi. Ebeveynlerin sosyodemografik özellikleri Tablo 1'de gösterilmiştir.

Tablo 1: Ebeveynlerin Sosyodemografik Özellikleri.

\begin{tabular}{|l|c|c|}
\hline \multicolumn{1}{|c|}{ Cinsiyet } & & \%/ss \\
\hline Kadın & 781 & 78,1 \\
\hline Yaş & 219 & 21,9 \\
\hline Eğitim & 35,00 & 5,69 \\
Okuryazar değil & 19 & \\
Okuryazar & 51 & 1,9 \\
İlköğretim & 134 & 5,1 \\
Lise & 580 & 13,4 \\
Üniversite & 216 & 58,0 \\
\hline
\end{tabular}

Çalışmaya dahil edilen ebeveynlerin çocuk say1s1 median değeri 1 idi (1-5). Ebeveynlerin 169'u alerjik hastalığ 1 mevcut olduğunu belirtmişken, 61 ebeveyn astım nedeniyle inhaler tedavi kullanmaktayd. Çocuğunda alerjik hastalık olduğunu ifade eden ebeveyn sayısı 149 idi (Tablo 2). Astım/alerjik bronşit olan 114 çocuğun 74'ü erkek olup ortalama yaşı $4,4 \pm 3,06$ yıl idi.

Tablo 2: Alerjik Hastallk Durumu.

\begin{tabular}{|l|c|c|}
\hline & n & \% \\
Yok & 831 & 83,1 \\
Var & 169 & 16,9 \\
\hline Çocuğunda alerjik hastalık & 851 & 85,1 \\
Yok & 149 & 14,9 \\
Var & 70 & 47 \\
Alerjik bronşit & 44 & 29,5 \\
Astım & 18 & 12,0 \\
Egzema & 4 & 2,7 \\
Saman nezlesi & 5 & 3,4 \\
Ürtiker & 8,4 \\
Belirtilmemiş & & \\
\hline
\end{tabular}


Astım tedavisinde kullanılan ilaçlarla ilgili bilgi durumunu değerlendirmeye yönelik sorulara verilen yanıtlara bakıldığında ebeveynleri tarafindan alerjik hastalığı olduğu bildirilen 149 çocuğun 111 'inde $(\% 74,5)$ astım/alerjik bronșit için ilaç kullanımı mevcuttu. İlaç olarak en sik $(\% 35,1)$ beta agonist+inhaler steroid kombinasyonu kullanılmaktaydı. İlaç kullananların 67'si $(\% 60,4)$ ilaçları sürekli kullanırken 44'ü $(\% 39,6)$ ilaçları şikayet olunca kullanmaktaydı. İlaçları sürekli kullanmama nedeni olarak en sik $(\% 50)$ ihmal cevab1 verildi. Cinsiyete ve eğitim durumuna göre ilaç kullanım özellikleri bakımından istatistiksel olarak anlamlı farklılık bulunmadi ( $>00,05)$ (Tablo 3).

Tablo 3: Astım İçin İlaç Kullanım Durumu.

\begin{tabular}{|l|c|c|}
\hline & n & \% \\
\hline İlaçların kullanılma sıklığı & 67 & 60,4 \\
Şikayet oldukça & 44 & 39,6 \\
\hline İlacı sürekli kullanmadığınızda & & \\
nedenleri & 22 & 50 \\
İhmal & 13 & 29,5 \\
İyileştiğini düşünme & 9 & 20,4 \\
\hline
\end{tabular}

Alerjik astımı ortaya çıkaran etkenler sorusuna en sik $(\% 50,1)$ bilmiyorum cevab1 verilirken, 2.s1klikta $(\% 39)$ ev tozu ve 3.s1kl1kta $(\% 5,8)$ evcil hayvan cevabı verildi. Çocuğu astım atağından korumak için alınabilecek önlemler sorusuna en s1k (\%52) bilmiyorum cevab1 verilirken, 2.s1kl1kta $(\% 35,5)$ tozsuz ortam/temizlik ve 3.s1kl1kta $(\% 9)$ dikkatli beslenme cevabı verildi (Şekil 1-2).

Astımı ortaya çıkardığ düşünülen etkenlere kadınlarda erkeklere göre polen cevabı verenlerin oranı istatistiksel olarak anlamlı derecede daha yüksek $(p<0,05)$ ve 'g1da' cevab1 verenlerin oran1 istatistiksel olarak anlamlı derecede daha düşük saptandı $(\mathrm{p}<0,01)$; astımı ortaya çıkardığı düşünülen etkenlere verilen diğer cevaplar bakımından cinsiyete göre istatistiksel olarak anlamlı farklılık bulunmadı $(\mathrm{p}>0,05)$. Eğitim durumuna göre astımı ortaya çıardığ 1 düşünülen etkenler ve çocuğu astım atağından korumak için alabilecekleri önlemler bakımından istatistiksel olarak anlamlı farklılık bulunmadi $(\mathrm{p}>0,05)$.

Çocuğunda alerjik hastalık varlığı ilköğretim mezunlarında okuryazarlara göre istatistiksel olarak anlamlı derecede daha düşük oranda saptandı (p:0,048). Alerjik hastalığı olanlarda alerjik hastalığ 1 olmayanlara göre çocuğunda alerjik hastalık varlığ 1 daha yüksek oranda olmakla birlikte farklılik istatistiksel olarak anlamlı değildi $(p>0,05)$; bu 2 grup arasında astım ortaya çıkardığ 1 düşünülen etkenler ve astım atağından korumak için alabile-

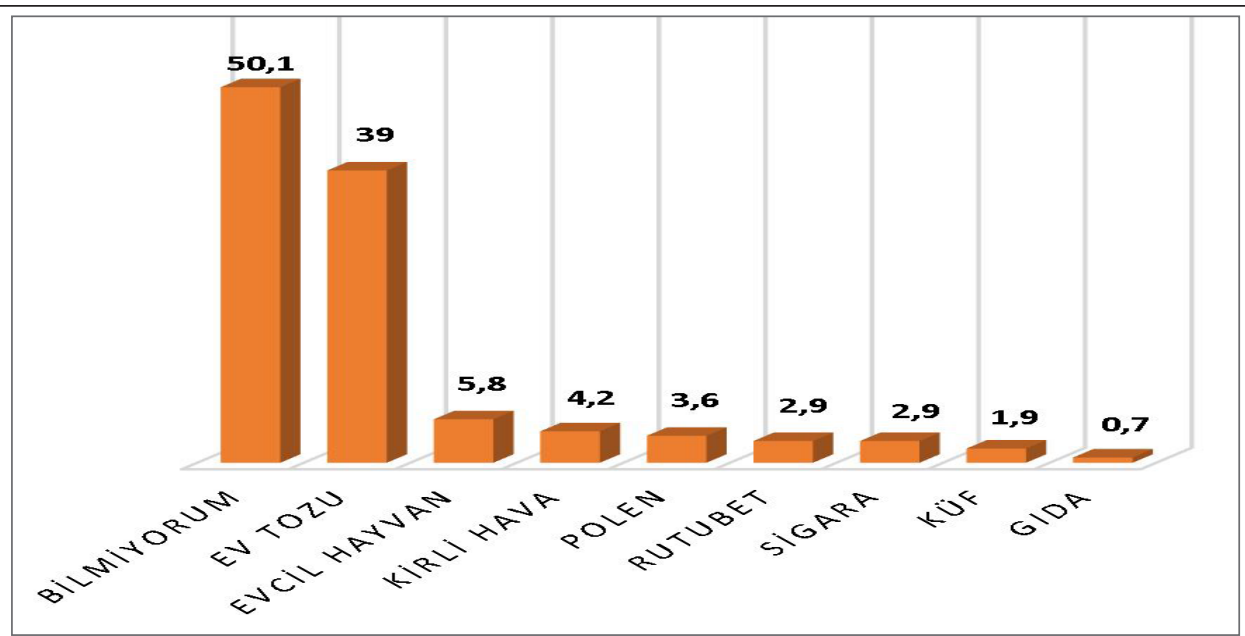

Şekil 1: “Alerjik Astımı Ortaya Çıkaran Etkenler” Anket Cevapları (\%).

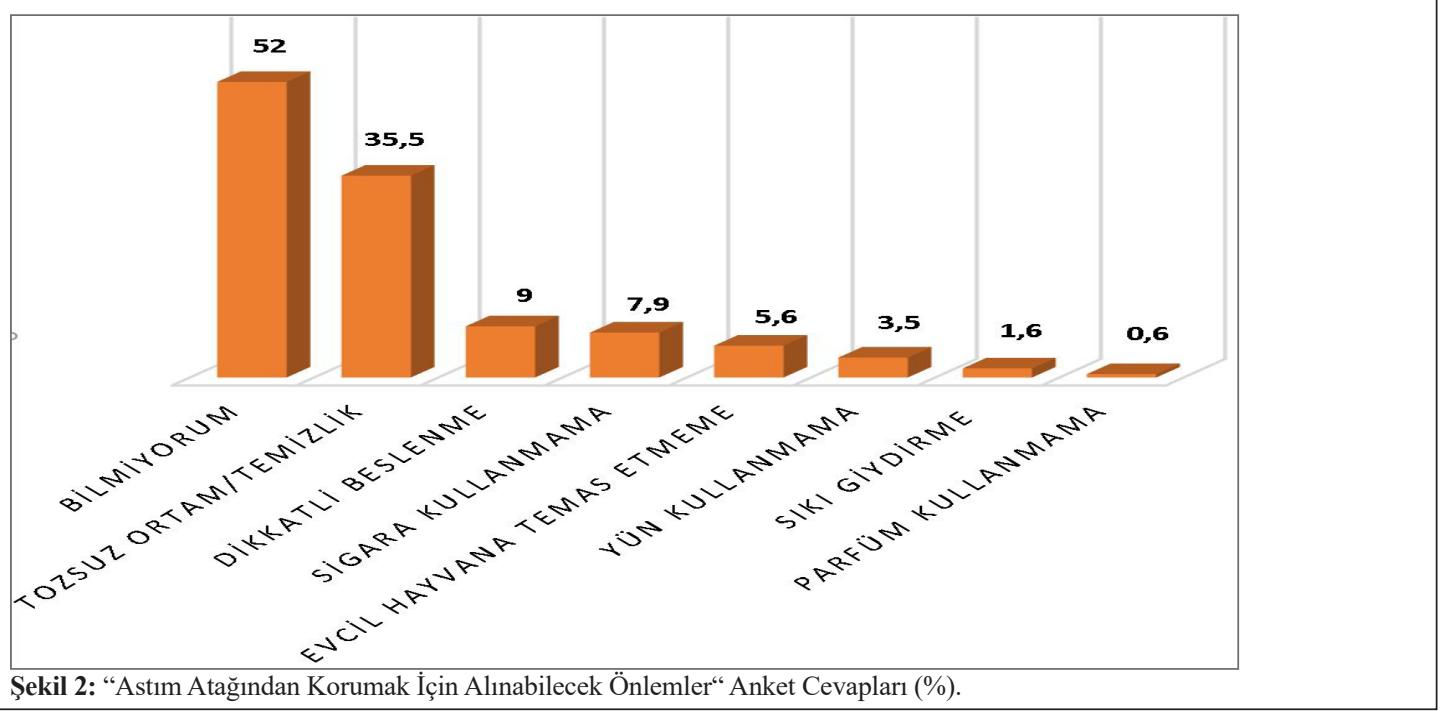


cekleri önlemler bakımından da istatistiksel olarak anlamlı farklı1ık bulunmadı $(\mathrm{p}>0,05)$. Çocuğunda alerjik hastalığı olanlarda çocuğunda alerjik hastalığı olmayanlara göre astımın ortaya çıkışının ev tozu, polen, rutubet, evcil hayvan, kirli hava, sigara, küf ve bazı gıdalardan kaynaklı olduğunu düşünenlerin oranları istatistiksel olarak anlamlı derecede daha yüksek ve bu soruya bilmiyorum cevabı verenlerin oranı istatistiksel olarak anlamlı derecede daha düşüktü $(p<0,001)$. Çocuğunda alerjik hastalığ 1 olanlarda çocuğunda alerjik hastalığı olmayanlara göre çocuğu astım atağından korumak için alabilecekleri önlemler sorusuna sigara kullanmama, yün ve parfüm kullanmama, evcil hayvanla temas etmeme, dikkatli beslenme ve sıkı giydirme cevaplarını verenlerin oranları istatistiksel olarak anlamlı derecede daha yüksek (parfüm kullanmama için $\mathrm{p}<0,05$ ve diğerleri için $p<0,001)$ ve bu soruya bilmiyorum cevabı verenlerin oranı istatistiksel olarak anlamlı derecede daha düşük $(\mathrm{p}<0,001)$ saptand1. Bu 2 grup arasında sadece çocuğu astım atağından korumak için alabilecekleri önlemler sorusuna tozsuz ortam/ temizlik cevabı verenlerin oranı bakımından istatistiksel olarak anlamlı farklılık bulunmadı $(\mathrm{p}>0,05)$ (Tablo 4).

Tablo 4: Çocukta Alerjik Hastalık Varlığına Göre Ebeveynin "Etkenler Ve Önlemler" Konusunda Bilgi Durumu.

\begin{tabular}{|c|c|c|c|c|c|}
\hline & \multicolumn{2}{|c|}{$\begin{array}{c}\text { Çocukta alerjik } \\
\text { hastalık yok }\end{array}$} & \multicolumn{2}{|c|}{$\begin{array}{l}\text { Çocukta alerjik } \\
\text { hastalık var }\end{array}$} & \multirow[b]{2}{*}{$\mathbf{p}$} \\
\hline & n & $\%$ & n & $\%$ & \\
\hline \multicolumn{6}{|l|}{$\begin{array}{l}\text { Alerjik astımı orta- } \\
\text { ya çıkardığı düşünü- } \\
\text { len etkenler }\end{array}$} \\
\hline Ev tozu & 306 & 36,0 & 84 & 56,4 & $0,0001 * * *$ \\
\hline Polen & 1 & 0,1 & 35 & 23,5 & $0,0001 * * *$ \\
\hline Rutubet & 8 & 0,9 & 21 & 14,1 & $0,0001 * * *$ \\
\hline Evcil hayvan & 35 & 4,1 & 23 & 15,4 & $0,0001 * * *$ \\
\hline Kirli hava & 12 & 1,4 & 30 & 20,1 & $0,0001 * * *$ \\
\hline Sigara & 15 & 1,8 & 14 & 9,4 & $0,0001 * * *$ \\
\hline Küf & 1 & 0,1 & 18 & 12,1 & $0,0001 * * *$ \\
\hline Gida & 0 & 0,0 & 7 & 4,7 & $0,0001 * * *$ \\
\hline Bilmiyorum & 477 & 56,1 & 24 & 16,1 & $0,0001 * * *$ \\
\hline \multicolumn{6}{|l|}{$\begin{array}{l}\text { Astım atağından } \\
\text { korumak için alabi- } \\
\text { lecekleri önlemler }\end{array}$} \\
\hline Bilmiyorum & 479 & 56,3 & 41 & 27,5 & $0,0001 * * *$ \\
\hline Sigara kullanmama & 34 & 4,0 & 45 & 30,2 & $0,0001 * * *$ \\
\hline Dikkatli beslenme & 33 & 3,9 & 57 & 38,3 & $0,0001 * * *$ \\
\hline Yün kullanmama & 6 & 0,7 & 29 & 19,5 & $0,0001 * * *$ \\
\hline $\begin{array}{l}\text { Parfüm kullan- } \\
\text { mama }\end{array}$ & 3 & 0,4 & 3 & 2,0 & $0,046^{*}$ \\
\hline $\begin{array}{l}\text { Tozsuz ortam/ } \\
\text { temizlik }\end{array}$ & 298 & 35,0 & 57 & 38,3 & 0,446 \\
\hline $\begin{array}{l}\text { Evcil hayvana } \\
\text { temas etmeme }\end{array}$ & 38 & 4,5 & 18 & 12,1 & $0,0001 * * *$ \\
\hline Sıkı giydirme & 5 & 0,6 & 11 & 7,4 & $0,0001 * * *$ \\
\hline
\end{tabular}

\section{TARTIŞMA}

Çalışmamızda alerjik astımı ortaya çıkaran ve astım atağından koruyan etkenler konusunda ebeveynlerin bilgi düzeyinin ölçülmesi amaçlandı ve bu düzeyin düşük olduğu saptand1. Ek olarak havayolu reaktivitesi tanımlanırken "alerjik bronşit" teriminin , "astım" dan daha fazla tercih edilen bir isimlendirme olduğu görüldü. Ebeveynlerin astım terimi kullanımını tercih etmemelerinin nedeni; astımı kronik, tedavisi zor ve ürkütücü bir hastalık; alerjik bronşiti ise geçici bir durum olarak değerlendirmeleri olabilir. Diğer bir sebep de hasta yakınına havayolu reaktivitesini açıklamak için doktor tarafından da alerjik bronşit terimi astımdan daha sık seçilmiş bir tanı olmuş olabilir.

Çalışmamızda sürekli tedavinin gerekliliği hakkında da bilgi eksikliği olduğu ve bu durumun astım ilaçlarının kullanımını etkilediği görülmüștür. İlaçları şikayet oldukça kullandığını bildiren 44 ebeveynin $\% 50$ 'si ihmal nedeniyle, $\% 29.5$ 'i ise iyileştiğini düșündüğü için sürekli ilaç kullanmadıklarını belirtmişlerdir. Hedenrud ve ark. yaptıkları benzer bir anket çalışmasında da asemptomatik dönemlerde ilacın gereksiz olduğu inancı nedeniyle ilaç uyumsuzluğu olabileceği vurgulanmıştır. Laforest ve ark. 'nın bir çalışmasında da katılımcıların üçte biri daha iyi hissettiklerinde inhale kortikosteroid kullanımını kesintiye uğrattıklarını bildirmişlerdir. Hasta ve hasta yakınlarının ilaçları düzenli kullanı$\mathrm{m} 1$ konusunda bilgilendirilmesi öncelikle hekimler için takibe ihtiyaç duyan bir eğitim görevidir. Bununla birlikte hastaların sağlık personeli tarafından verilen bilgiyi unutma eğiliminde olması da önemli bir zorluktur. Astım ilaçları satın alınan eczanelerde de bilgilendirme mutlaka yapılmalı, rutin kontrollerde hekim ve hemşireler tarafindan bilgilendirmeler tekrarlanmalidır $(13,14)$.

Simba ve arkadaşlarının astımlı hastaya bakım vericilerle yaptığı bir anket çalışmasında, astımı tetikleyen etkenler sorgulandığında \%56.9 oranında kötü kokulu kimyasallar, \% 87.07 oranında soğuk hava ve \% 62.93 oranında güçlü parfümlerin astım11 hastayı tetiklediği cevabı alınmıştır (15). Çok az sayıda kişi (\% 21.55 ) duygusal stres, (\% 47.4) egzersiz, (\% 11.21) hamamböceği ve (\% 9.48) aspirin / ibuprofen şıkkını işaretlemişlerdir. Bakım vericiler soruların yarısından fazlasına doğru cevap vererek \% 72,4 ile bilgi düzeyinin oldukça yüksek olduğunu göstermişlerdir. Bu çalışmada bakım vericilerin $\% 38$ 'i üniversite mezunu iken; \%2 hasta hiç eğitim almamış kişilerdi. Bizim çalışmamızda ise tüm ebeveynlere baktığımızda çocuğu astım atağından korumak için alabilecekleri önlemler sorusuna en s1k (\%52) bilmiyorum cevab1 verilirken, 2.s1kl1kta $(\% 35,5)$ tozsuz ortam/temizlik ve 3.s1klikta $(\% 9)$ dikkatli beslenme cevabı verildi. Bizim çalışmamızdaki ebeveynlerin \% 7'si ilkokula dahi gitmemiş (okuryazar değil+okuryazar) ; üniversite mezunu sayısı ise \%21 idi. Çalışmamızda eğitim durumuna göre cevaplar bakımından istatistiksel olarak anlamlı farklılık bulunmamıştı ancak "astımı ortaya çıkaran etkenler" ve "koruyucu önlemler" sorusuna en sık bilmiyorum cevabının verilmiş olmasının Simba ve arkadaşlarının yaptığı çalışmaya kıyasla 
çalışma popülasyonumuzdaki daha düşük eğitim seviyesinden kaynaklandığını düşünmekteyiz. Ancak çocuğunda alerjik hastalık olan ebeveynlerde "astımı ortaya çıkaran etkenler" ve "astım atağından korumak için alınabilecek önlemler" sorularına "bilmiyorum" cevab1 verenlerin oran1 istatistiksel olarak anlamlı derecede daha düşük bulunmuştur $(p<0,001 ; p<0,001)$. Alerjik bir çocuk ile günlük yaşamın doğal olarak ebeveynler için daha fazla öğrenmeyi sağladığını düşünmekteyiz.

Benzer şekilde İspanya'nın Kanarya Adaları'nda yapılan bir araştırmada, bir acil merkezde 95 astımlı çocuğun ebeveynleri görülmüş, bu ebeveynlerin yaklaşı $\%$ 80'inin astım alevlenmelerinin ana tetikleyici faktörlerini nasıl tanımlayacağını bilmediği gösterilmiştir(16).

Yine Roncada ve arkadaşlarının yaptığı bir çalışmada da ebeveynlere uygulanan anketler neticesinde ebeveynlerin astım hakkında yeterli bilgi seviyesinden daha düşük düzeyde olduğu gösterilmiştir (17). Farklı çalışmalarda sunulan bu sonuçlar arasındaki benzerlik, ebeveynlerin bilgi eksikliğinin farklı popülasyonlarda bir gerçek olduğunu ortaya koymaktadır.

Çalışmamızda ebeveynlerin sigara içme durumu sorgulanmadığı için sigara kullanımı ile ebeveyn bilgi düzeyi arasındaki ilişki değerlendirilemedi. Ancak çalışmamızda astım ortaya çıkaran etkenler sorusuna "sigara" cevabı verilme oranının düşük $(\% 2,9)$ olması dikkat çekicidir. Bu konuda ailelerin bilgi düzeyinin, toplumsal farkındalığın artırılması gerekmektedir.

Roncada ve arkadaşlarının yaptığı çalışmada astımlı hastaların ebeveynleri çocuk gögüs hastalıkları polikliniğinden seçilmiş ve validiye edilmiş NACQ anket formu kullanılarak cevaplara göre bir skorlama sistemi yapılmış (17). Bizim popülasyonumuzda hastalar genel pediatri polikliniğinden seçilmiş, çalışmadaki tanılar hastaların beyanına göre yer almış ve anket formunda bir skorlama sistemi kullanılmamıştır. Bu açılardan tanıların güvenilirliği daha düşüktür, bu durum çalışmamızın kısıtlılıklarından biridir.

\section{SONUÇ}

Çocuğunda alerjik hastalık mevcut olan hasta yakınlarının alerjik astımı ortaya çıkaran etkenler ve astımdan koruyucu önlemler konusunda bilgi düzeyleri diğer hasta yakınlarına kıyasla daha yüksektir ancak tüm çalışmadaki ebeveynler değerlendirildiğinde etkenler ve koruyucu önlemler sorularına verilen "bilmiyorum" cevabının fazlalığı ile ihmal ve iyileştiğini düşünme nedeniyle sürekli ilaç kullanımın aksatılıyor olması bilgi düzeyinin yeterli olmadığını göstermektedir. Toplumda her an astımlı bir birey ile karşılaşma, ortak yaşama olasılığımız olduğundan astımın iyi kontrolü için tüm bireylerin semptomlar, tetikleyici faktörler ve koruyucu önlemler açısından bilgi düzeylerinin artırılması gerekmektedir. Astımlı çocuğu olan ebeveynlere hastalık ve tedavinin önemi konusunda yeterli eğitim verilmelidir.

\section{$K A Y N A K L A R$}

1. Global Strategy for Asthma Management and Prevention (2018 update) GINA, https://ginasthma.org/wp-content/uploads/2019/01/2018-GINA.pdf

2. Ober C. Perspectives on the past decade of asthma genetics. J Allergy Clin Immunol 2005;116:274-8.

3. Holgate ST. Genetic and environmental interaction in allergy and asthma. J Allergy Clin Immunol 1999;104:1139-46.

4. Türk Toraks Derneği Astım Tanı ve Tedavi Rehberi 2016, https://www.toraks.org.tr/uploadFiles/book/file/1082017TTD-Astim-Tani-ve-Tedavi-Rehberi-2016.pdf

5. Propp P, Becker A. Prevention of asthma: where are we in the 21st century? Expert Rev Clin Immunol 2013;9:1267-78.

6. Lau S. What is new in the prevention of atopy and asthma? Curr Opin Allergy Clin Immunol 2013;13:181-6.

7. Arshad SH. Primary prevention of asthma and allergy. J Allergy Clin Immunol 2005;116:3-14.

8. Sheikh SI, Chrysler M, Ryan-Wenger NA, Hayes D Jr, McCoy KS. Improving Pediatric Asthma Care: A Partnership between Pediatric Primary Care Clinics and a Free-Standing Children's Hospital. J Asthma 2015:1-26.

9. DeWalt D, Dilling N, Rosenthal M, Pignone M: Low parental literacy is associated with worse asthma care measures in children. Ambul Pediatr 2007, 7:25-31.

10. Lavoie KL, Bouchard A, Joseph M, Campbell TS, Favreau H, Bacon SL: Association of asthma self-efficacy to asthma control and quality of life. Ann Behav Med 2008, 36:100-106.

11. Owton H, Allen-Collinson J, Siriwardena AN. Using a narrative approach to enhance clinical care for patients with asthma. Chest 2015:288-93.

12. Andrews, $K L$, Jones SC, Mullan J. Asthma self management in adults: A review of current literature. Collegian: Australian J Nursing Practice, Scholarship and Research 2013

13. Laforest L, El Hasnaoui A, Pribil C, Ritleng C, Osman LM, Schwalm MS, et al. Asthma patients' self-reported behaviours toward inhaled corticosteroids. Respir Med. 2009;103(9):1366-75.

14. Hedenrud T, Jakobsson A, El Malla H, Håkonsen H. I did not know it was so important to take it the whole time" self-reported barriers to medical treatment among individuals with asthma. BMC Pulm Med. 2019;18;19(1):175.

15. Simba J, Marete I, Waihenya R, Kombe Y, Mwangi A, Mburugu P, Ogaro F. Knowledge and perceptions on childhood asthma among care-takers of children with asthma at a National Referral Hospital in Western Kenya: a descriptive study. Afri Health Sci. 2018;18(4): 965-971.

16. Garcia-Luzardo MR, Aguilar-Fernández AJ, Rodríguez-Calcines N, Pavlovic-Nesic S. Conocimientos acerca del asma de los padres de niños asmáticos que acuden a un servicio de urgencias. Acta Pediatr Esp. 2012;70(5):196-203.

17. Roncada C, Cardoso TA, Buganca BM, Bischoof LC, Soldera K, Pitrez PM. Levels of knowledge about asthma of parents of asthmatic children. Einstein (Sao Paulo)2018; 7 ;16 (2) 